\section{TRAINING ACRYLIC SKILLS IN EMPOWERING WOMEN IN THE SERVICE OF WOMEN \\ EMPOWERMENT AND CHILD PROTECTION}

\section{PELATIHAN KETERAMPILAN AKRILIK DALAM PEMBERDAYAAN PEREMPUAN DI DINAS PEMBERDAYAAN PEREMPUAN DAN PERLINDUNGAN ANAK}

Jurnal Pendidikan Luar Sekolah

http://kolokium.ppj.unp.ac.id/ Jurusan Pendidikan Luar Sekolah Fakultas Ilmu Pendidikan Universitas Negeri Padang Sumatera Barat, Indonesia

Volume 9, Nomor 1, 2021 DOI: $10.24036 /$ kolokium-pls.v9i1.461

Received 13 Maret 2021 Approved 08 April 2021 Published 22 April 2021

\author{
Vira Shavira ${ }^{1}$ \\ ${ }^{1}$ Universitas Singaperbangsa Karawang \\ 2virashavirajauhari@gmail.com
}

\begin{abstract}
The training has elements such as training containing the objectives to be achieved, training takes place outside the school system, and training provides knowledge and skills to improve the quality of life. The process of community empowerment through out-of-school education is actually an effort that enables the community with all its empowerment to empower itself. With the center of activity should be in the hands of the people themselves with starting point from the community, carried out by the community and its benefits for the community or in other terms community-based education. The condition of women in Indonesia today is very alarming, women are seen as weak and only considered as someone who is only able to carry out their duties as a housewife. In addition, with the patriaki culture still prevailing in Indonesian society. The state of patriarchal culture directly or indirectly places women in the lower classes after men. Finally what happens is the dichotomy, which is the ruling society and the ruling humans. To free the situation of mastering and being controlled, liberation must be carried out through the process of empowering those who are controlled (empowerment of the powerless). Empowerment or empowerment can be interpreted as providing power or strength to someone because he is considered helpless or the strength that is so small that he can hardly do anything. In Dinas Pemberdayaan Perempuan dan Perlindungan Anak Kabupaten Karawang there are several fields and one of them is a field Peningkatan Kualitas Hidup Perempuan and Keluarga This field has the main task of carrying out part of the duties of the Head of Service in terms of facilitation, coordination, management, guidance and monitoring and evaluation of the implementation of women's empowerment and increasing family security. Therefore effort Dinas Pemberdayaan Perempuan dan Perlindungan anak in empowering women by forming groups named after them PEKKA located in the Desa Mekarjati. PEKKA is is an abbreviation of Perempuan Kepala Keluarga. This study aims to determine and describe the process of acrylic skills training, then what are the supporting and inhibiting factors in training and also how are the results of acrylic skills training in empowering women in Dinas Pemberdayaan Perempuan Dan Perlindungan Anak. This research is a qualitative research with case study method whose data is obtained from interviews and this research was conducted at Dinas Pemberdayaan Perempuan Dan Perlindungan Anak Karawang
\end{abstract}


Based on the results of the analysis and discussion, it can be concluded that the Pelatihan Keterampilan Akrilik Dalam Pemberdayaan Perempuan in the Dinas Pemberdayaan Perempuan Dan Perlindungan Anak Karawang District has been quite successful in providing training to PEKKA members to empower women who have become PEKKA members in Desa Mekarjati Karawang Regency.

Keywords: Acrylic Skills Training, Women's Empowerment.

\begin{abstract}
ABSTRAK
Pelatihan memiliki unsur-unsur seperti pelatihan yang memuat tujuan yang ingin dicapai, pelatihan berlangsung di luar sistem sekolah, dan pelatihan memberikan pengetahuan dan keterampilan untuk meningkatkan kualitas hidup. Proses pemberdayaan masyarakat melalui pendidikan luar sekolah sebenarnya merupakan upaya yang memungkinkan masyarakat dengan segala keberdayaannya untuk memberdayakan dirinya sendiri. Dengan pusat kegiatan harus berada di tangan masyarakat itu sendiri dengan titik tolak dari masyarakat, dilakukan oleh masyarakat dan manfaatnya bagi masyarakat atau dalam istilah lain pendidikan berbasis masyarakat. Kondisi perempuan di Indonesia saat ini sangat memprihatinkan, perempuan dipandang lemah dan hanya dianggap sebagai seseorang yang hanya mampu menjalankan tugasnya sebagai ibu rumah tangga. Selain itu, dengan budaya patriaki yang masih berlaku di masyarakat Indonesia. Keadaan budaya patriarki secara langsung atau tidak langsung menempatkan perempuan pada kelas bawah setelah laki-laki. Akhirnya yang terjadi adalah dikotomi, yaitu masyarakat yang berkuasa dan manusia yang berkuasa. Untuk membebaskan situasi menguasai dan dikuasai, maka pembebasan harus dilakukan melalui proses pemberdayaan mereka yang dikuasai (empowerment of the powerless). Pemberdayaan atau pemberdayaan dapat diartikan sebagai pemberian daya atau kekuatan kepada seseorang karena ia dianggap tidak berdaya atau kekuatan yang begitu kecil sehingga ia hampir tidak dapat berbuat apa-apa. Di Dinas Pemberdayaan Perempuan dan Perlindungan Anak Kabupaten Karawang terdapat beberapa bidang salah satunya bidang Peningkatan Kualitas Hidup Perempuan dan Keluarga Bidang ini mempunyai tugas pokok melaksanakan sebagian tugas Kepala Dinas dalam hal fasilitasi, koordinasi, pengelolaan, pembinaan dan pemantauan serta evaluasi pelaksanaan pemberdayaan perempuan dan peningkatan keamanan keluarga. Oleh karena itu upaya Dinas Pemberdayaan Perempuan dan Perlindungan anak dalam pemberdayaan perempuan dengan membentuk kelompok yang diberi nama PEKKA yang berlokasi di Desa Mekarjati. PEKKA adalah singkatan dari Perempuan Kepala Keluarga. Penelitian ini bertujuan untuk mengetahui dan mendeskripsikan proses pelatihan keterampilan akrilik, kemudian apa saja faktor pendukung dan penghambat dalam pelatihan dan juga bagaimana hasil pelatihan keterampilan akrilik dalam pemberdayaan perempuan di Dinas Pemberdayaan Perempuan Dan Perlindungan Anak. Penelitian ini merupakan penelitian kualitatif dengan metode studi kasus yang datanya diperoleh dari wawancara dan penelitian ini dilakukan di Dinas Pemberdayaan Perempuan Dan Perlindungan Anak Karawang Berdasarkan hasil analisis dan pembahasan dapat disimpulkan bahwa Pelatihan Keterampilan Akrilik Dalam Pemberdayaan Perempuan di Dinas Pemberdayaan Perempuan Dan Perlindungan Anak Kabupaten Karawang cukup berhasil memberikan pelatihan kepada anggota PEKKA untuk memberdayakan perempuan yang telah menjadi anggota PEKKA di Desa Mekarjati Kabupaten Karawang.
\end{abstract}

Kata Kunci: Pelatihan Keterampilan Akrilik, Pemberdayaan Perempuan 
Training Acrylic Skills in Empowering Women in the Service of Women...

\section{PENDAHULUAN}

Kebutuhan pendidikan tidak hanya didapatkan di pendidikan formal saja, melainkan dapat diakses di pendidikan informal dan pendidikan nonformal. Di dalam pendidikan nonformal, kebutuhan pendidikan individu atau kelompok dapat dipenuhi sesuai dengan kebutuhan individu atau kelompok tersebut (Sutarto, 2017). Pengembangan pendidikan nonformal di masa yang akan datang perlu memperhatikan beberapa hal sebagai beriku seperti dikatan oleh Sudjana (2004), yaitu: pertama pendidikan nonformal perlu lebih proaktif dalam mereformasi visi, misi dan strateginya untuk mengubah program-program pendidikan yang sedianya berorientasi untuk menghasilkan para lulusan sebagai pencari kerja (worker society) menjadi upaya menghasilkan lulusan yang memiliki keahlian dan kemampuan untuk mandiri dan pencipta lapangan kerja (employee society), kedua; unsur-unsur sistem pendidikan nonformal perlu dilakukan secara lengkap dan utuh, yaitu mencakup komponen, proses dan tujuan, ketiga; meningkatkan visi misi dan strategi pengembangan pendidikan nonformal, keempat; pendidikan nonformal meningkatkan orientasi keberpiakannya kepada orang banyak, kelima; pendidikan kelembagaannya dengan upaya penelitian, manajemen dan produksi keenam; dalam meningkatkan misi pendidikan nonformal yang demikian luas maka lembaga-lembaga penyelenggara dan pelaksana program-program pendidikan tidak dapat bekerja sendiri-sendiri tanpa ada keterkaitan dengan pihak-pihak lain.

Dalam tulisan ini yang dimaksud dengan strategi pengembangan pendidikan luar sekolah adalah upaya tindakan yang proaktif untuk mereformasi visi misi dan upaya untuk mengubah program yang berorientasi pencari kerja menjadi lulusan yang ahli dan profesional serta mandiri untuk menciptakan lapangan kerja. Menurut Undang-Undang Nomor 20 tahun 2003 tentang Sistem Pendidikan Nasional, pasal 26 ayat (4) dinyatakan bahwa Lembaga pelatihan merupakan satuan pendidikan nonformal, di samping satuan pendidikan lainnya yaitu kursus, kelompok belajar, majelis ta'lim, kelompok bermain, taman penitipan anak, pusat kegiatan belajar masyarakat, serta satuan pendidikan yang sejenis. Pelatihan dapat dilakukan dalam jenis dan ruang lingkup pendidikan nonformal.

Pendidikan nonformal tidak memiliki batasan usia setiap individu yang ingin tetap belajar. Dalam upaya untuk mewujudkan bahwa tiap-tiap warga Negara berhak atas pekerjaan dan penghidupan yang layak bagi kemanusiaan dan mengurangi angka pengangguran salah satunya dengan diadakannya pendidikan dan pelatihan, karena pendidikan dan pelatihan merupakan salah satu wujud dari kebudayaan manusia, dimana kebudayaan itu sendiri selalu tumbuh dan berkembang mengikuti dinamika perkembangan zaman, penyempurnaan sistem pendidikan dan pelatihan perlu dilakukan terus menerus dan sistematika, selain itu menyesuaikan dunia pendidikan dengan kebutuhan dan perkembangan ilmu dan teknologi dalam masyarakat, juga untuk menjawab tantangan masa depan (Sari, 2016; Yusuf, 2014). Menurut Undang-Undang Nomor 20 tahun 2003 tentang Sistem Pendidikan Nasional, Pasal 26 Ayat 5 "Pelatihan diselenggarakan bagi masyarakat yang memerlukan bekal pengetahuan, keterampilan, kecakapan hidup, dan sikap untuk mengembangkan diri, mengembangkan profesi, bekerja, usaha mandiri dan atau melanjutkan pendidikan ke jenjang yang lebih tinggi". Keterampilan atau keahlian yang menjadi fokus pendidikan luar sekolah tersebut, akan sangat berguna bagi masyarakat dalam mencari nafkah untuk membiayai berbagai kegiatan hidupnya (Sudarsana, 2015; Syamsi, 2010; Yuse, Jamaris, \& Ismaniar, 2018). Ketika semua masyarakat mampu menggerakkan ekonomi keluarga yang berakibat pada pemenuhan kebutuhan, mungkin pemerintah tidak harus lagi pusing memikirkan adanya pengangguran dan kemiskinan di republik ini. 
Manusia yang berkualitas secara kognitif, afektif, psikomotor, emosi dan spirit insaniah adalah modal utama ketika peradaban makin modern. Selain itu, dengan masih adanya budaya patriaki yang masih berlaku di masyarakat Indonesia. Keadaan budaya patriaki secara langsung maupun tidak langsung menempatkan kaum perempuan di kelas bawah setelah laki-laki (Israpil, 2017; Rafi, 2010; Sakina \& Siti, 2017; Susanto, 2015). Pemberdayaan atau empowerment dapat diartikan memberikan daya atau kekuatan kepada seseorang karena dia dianggap tak berdaya atau kekuatan yang ada sangat kecil sehingga hampir tidak dapat berbuat apa-apa (Saugi \& Sumarno, 2015; Shavira \& Khoeriasih, 2020; Suarsa \& Sutajaya, 2015). Sumber daya manusia merupakan modal yang sangat penting dalam melakukan pembangunan. Keterkaitan masalah ini dengan pemberdayaan masyarakat sangat besar. Berdasarkan hasil observasi di Dinas Pemberdayaan Perempuan dan Perlindungan Anak Kabupaten Karawang tersebut ada beberapa bidang dan salah satunya yaitu bidang Peningkatan Kualitas Hidup Perempuan dan Keluarga. Bidang ini mempunyai tugas pokok melaksanakan sebagian tugas Kepala Dinas dalam hal fasilitasi, koordinasi, pengelolaan, pembinaan serta monitoring dan evaluasi penyelenggaraan pemberdayaan perempuan dan peningkatan ketahanan keluarga.

Maka dari itu upaya Dinas Pemberdayaan Perempuan dan Perlindungan anak dalam pemberdayaan perempuan yaitu dengan cara membentuk kelompok yang dinamai PEKKA yang bertempat di Desa Mekarjati Kecamatan Karawang Barat. PEKKA adalah singkatan dari Perempuan Kepala Keluarga. Dalam pemberdayaan perempuan tersebut, Dinas Pemberdayaan Perlindungan Anak memberikan suatu pelatihan keterampilan akrilik guna meningkatkan kualitas ketahanan hidup perempuan. Dari uraian tersebut diatas, penulis tertarik ingin mengetahui proses pelatihan keterampilan tersebut, lalu ingin mengetahui apa saja yang menjadi faktor pendukung dan penghambat dari pelatihan keterampilan itu, dan juga tidak lupa bagaimana hasil yang telah dicapai.

\section{METODE}

Penelitian ini menggunakan pendekatan kualitatif dengan metode studi kasus. Penelitian ini difokuskan pada suatu kasus tertentu yaitu pelatihan keterampilan dalam pemberdayaan perempuan di Dinas Pemberdayaan Perempuan Dan Perlindungan Anak Kabupaten Karawang. Penelitian ini dilakukan guna mengetahui proses secara spesifik bagaiamana proses, faktor pendukung dan penghambat, serta hasil dari pelatihan keterampilan akrilik dalam pemberdayaan perempuan di Dinas Pemberdayaan Perempuan Dan Perlindungan Anak Kabupaten Karawang. Adapun subjek yang akan diteliti dalam penelitian ini adalah kasie pemberdayaan perempuan dan instruktur pelatihan. Serta dua orang peserta pelatihan yang dapt memberikan informasi tentang proses, faktor pendukung dan penghambat, dan hasil.

\section{PEMBAHASAN}

Yang melatar belakangi adanya pelatihan keterampilan akrilik yaitu karena masih banyaknya anggota PEKKA yang masih termaginal kan di masyarakat sekitar. Ingin membagi ilmu yang telah dimiliki dan mencoba memberikan solusi bagi ibu-ibu rumah tangga atau remaja perempuan untuk memiliki penghasilan tambahan dengan menjual hasil dari ilmu yang di dapat. Sehingga pihak DP3A ingin mengangkat harkat dan martabat anggota PEKKA dengan memberikan pelatihan keterampilan dan memberikan solusi bagi ibu-ibu 
Training Acrylic Skills in Empowering Women in the Service of Women...

dan remaja perempua dalam memanfaatkan atau memberdayakan waktu agar dapat bermanfaat dengan menghasilkan ilmu yang di dapat. Tujuan memberikan pelatihan yaitu agar anggota PEKKA mempunyai keahlian dalam keterampilan akrilik atau melatih kaum ibu-ibu rumah tangga atau remaja perempuan untuk memperoleh keahlian dalam membuat rangkaian Bunga dari akrilik dan memanfaatkan waktu luang yang terbuang. Peran pengorganisasian kelompok sangat penting karena dapat menumbuhkan rasa semangat dalam proses pelatihan, sehingga pelatihan dapat dilaksanakan dengan penuh antusias dari setiap kelompok menyatakan peran pengorganisasian kelompok dalam mendukung keberhasilan pelatihan yaitu pertama dalam pelaksanaan pelatihan di buatkan dan di bentuk kelompok usaha di maksudkan mempermudah dan saling menunjang sesame peserta lain nya untuk menyamakan tingkat pemahaman dan keterampilan karena peserta di latar belakangi perbedaan pendidikan dan potensi dirinya (Aslichati, 2011). Lalu juga ada peningkatan pengetahuan dari hasil pelatihan yang di dapat peserta pelatihan sangat terlihat ketika mereka bisa langsung mempraktikan membuat keterampilan akrilik. Peningkatan sikap dari hasil pelatihan sanngat terlihat oleh instruktur. Yaitu, peserta pelatihan jadi gampang bersosalisasi dengan kelompok yang lainnya dan juga tidak malu-malu lagi dalam berpendapat dan bertanya. Dan juga peningkatan keterampilan yang di dapatkan dari hasil pelatihan tentu sudah jelas, peserta pelatihan yang tujuannya mengikuti pelatihan untuk mendapatkan keterampilan memang benar adanya.

\section{KESIMPULAN}

Berdasarkan penelitian yang sudah dilakukan, tujuan memberikan pelatihan yaitu agar anggota PEKKA mempunyai keahlian dalam keterampilan akrilik atau melatih kaum ibu-ibu rumah tangga atau remaja perempuan untuk memperoleh keahlian dalam membuat rangkaian Bungan dari akrilik dan memanfaatkan waktu luang yang terbuang. Pendekatan yang digunakan dalam pelatihan yaitu terutama dengan melalui pendekatan identifikasi pada masyarakat Desa Mekarjati dengan tujuan memberikan maskud dan tujuan di adakan nya pelatihan, disaat masyarakat sudah paham lalu masyarakat di ajak untuk mengikuti pelatihan. Materi yang di berikan oleh instruktur dapat mudah di pahami sehingga para peserta didik dengan mudahnya dapat memahami semua materi yang di berikan.dan tentunya pengetahuan yang di dapat sangat bermanfaat untuk orang-orang di sekitarnya. Peningkatan keterampilan yang di dapatkan dari hasil pelatihan tentu sudah jelas, peserta pelatihan yang tujuannya mengikuti pelatihan untuk mendapatkan keterampilan memang benar adanya.

\section{DAFTAR RUJUKAN}

Aslichati, L. (2011). Organisasi Pemberdayaan dan Kesejahteraan Keluarga Sebagai Sarana Pemberdayaan Perempuan. Jurnal Organisasi Dan Manajemen, 7(1). Retrieved from www.jurnal.ut.ac.id/index.php/jom/article/download/77/64

Israpil, I. (2017). Budaya Patriarki dan Kekerasan Terhadap Perempuan (Sejarah dan Perkembangannya). Jurnal Pusaka, 5(2).

Rafi, M. (2010). Budaya Patriarkhi dan Perjuangan Perempuan dalam Novel Pesan Cinta Dari Hujan Karya Erni Aladjai. Lensa: Kajian Kebahasaan, Kesusastraan Dan Budaya, $7(2)$.

Sakina, A., \& Siti, D. H. (2017). Menyoroti Budaya Patriarki di Indonesia. Share Social Work 
Journal, 7. https://doi.org/10.24198/share.v7i1.13820

Sari, R. (2016). Pemberdayaan Masyarakat Melalui Pengembangan Usaha Pariwisata. Jurnal Al-Bayan, 22(34).

Saugi, W., \& Sumarno, S. (2015). Pemberdayaan Perempuan Melalui Pelatihan Pengolahan Bahan Pangan Lokal. Jurnal Pendidikan Dan Pemberdayaan Masyarakat, 2(2). Retrieved from https://journal.uny.ac.id/index.php/jppm/article/view/6361/6481

Shavira, V., \& Khoeriasih, N. (2020). Pelatihan Keterampilan Akrilik dalam Pemberdayaan Perempuan di Dinas Pemberdayaan Perempuan dan Perlindungan Anak. JoCE; Journal of Community Education, 1(2).

Suarsa, P. W., \& Sutajaya, M. (2015). Pemberdayaan Masyarakat Melalui Pelatihan ErgoEntrepreneurship untuk Mengembangkan Pengetahuan dan Sikap Kewirausahaan Serta Meningkatkan Pendapatan Pedagang Kuliner Lokal di Desa Peliatan, Ubud, Gianyar. Jurnal Ilmu Sosial Dan Humaniora, 4(2).

Sudarsana, I. K. (2015). Peningkatan Mutu Pendidikan Luar Sekolah dalam Upaya Pembangunan Sumber Daya Manusia. Jurnal Penjaminan Mutu, Volume 1, 1-14. https://doi.org/10.25078/jpm.v1i1.34

Sudjana, D. (2004). Pendidikan Non Formal. Bandung: Falah Production.

Susanto, N. H. (2015). Tantangan Mewujudkan Kesetaraan Gender. MUWAZAH, 7(2).

Sutarto, J. (2017). Pendidikan Nonformal Teori dan Program. Semarang: Widya Karya.

Syamsi, I. (2010). Pendidikan Luar Sekolah sebagai Pemberdaya Masyarakat. Diklus, 14(1), 66-76.

Retrieved

from https: / www.google.com/url?sa $=$ t\&rct $=j \& q=\& e s r c=s \&$ source $=$ web\&cd $=1 \& c a d=r$ ja\&uact $=8 \&$ ved $=2$ ahUKEwi8x4jxqaHeAhUIeysKHWV2A4QQFjAAegQICRAC\& url $=$ https $\% 3 \mathrm{~A} \% 2 \mathrm{~F} \% 2 \mathrm{Fmedia}$.neliti.com $\% 2$ Fmedia $\% 2$ Fpublications $\% 2 \mathrm{~F} 217817$ pendidikan-luar-sekolah-sebagai-pemberda.pdf\&usg=AOvVaw3HPh

Undang-Undang Nomor 20 tahun 2003 tentang Sistem Pendidikan Nasional. Retrieved from http://dispora.slemankab.go.id/wp-content/uploads/2018/05/UU-Nomor-20tahun-2003-ttg-sistem-pendidikan-nasional.pdf

Yuse, A. P., Jamaris, J., \& Ismaniar, I. (2018). Penerapan Pembelajaran Orang Dewasa oleh Instruktur Pelatihan Keterampilan Menjahit di SPNF SKB Lima Puluh Kota. Spektrum: Jurnal Pendidikan Luar Sekolah (PLS), 1(1), 16. https://doi.org/10.24036/spektrumpls.v1i1.9199

Yusuf, A. (2014). Analisis Kebutuhan Pendidikan Masyarakat. Jurnal Penelitian Pendidikan, 31(2). Retrieved https://journal.unnes.ac.id/nju/index.php/JPP/article/view/5690/4561. 